Retinal Angiography and Optical Coherence Tomography 


\section{Retinal Angiography and Optical Coherence Tomography}

Edited by

J. Fernando Arevalo, MD, FACS

Professor and Chairman, Retina and Vitreous Service, Clinica Oftalmológica Centro Caracas,

The Arevalo-Coutinho Foundation for Research in Ophthalmology, Caracas, Venezuela 
J. Fernando Arevalo, MD, FACS

Professor and Chairman, Retina and Vitreous Service, Clinica Oftalmológica Centro Caracas,

The Arevalo-Coutinho Foundation for Research in Ophthalmology, Caracas, Venezuela

ISBN: 978-0-387-68986-9

e-ISBN: 978-0-387-68987-6

DOI: $10.1007 / 978-0-387-68987-6$

Library of Congress Control Number: 2008936992

(C) 2009 Springer Science + Business Media, LLC

All rights reserved. This work may not be translated or copied in whole or in part without the written permission of the publisher (Springer Science + Business Media, LLC, 233 Spring Street, New York, NY 10013, USA), except for brief excerpts in connection with reviews or scholarly analysis. Use in connection with any form of information storage and retrieval, electronic adaptation, computer software, or by similar or dissimilar methodology now known or hereafter developed is forbidden.

The use in this publication of trade names, trademarks, service marks, and similar terms, even if they are not identified as such, is not to be taken as an expression of opinion as to whether or not they are subject to proprietary rights.

While the advice and information in this book are believed to be true and accurate at the date of going to press, neither the authors nor the editors nor the publisher can accept any legal responsibility for any errors or omissions that may be made. The publisher makes no warranty, express or implied, with respect to the material contained herein.

Printed on acid-free paper

98776554321

springer.com 
To my parents:

Who gave me a wonderful life, and all the support and opportunities

To my wife, Oly:

Who has taught me how to be a better human being, who has beared with me for so many years, and has shared the good and the bad

To my son, Fernando Andrés:

Who has taught me how much my parents loved me, and for all the happiness he has brought to us 


\section{Preface}

After more than 40 years since the introduction of fluorescein angiography (FA), more than 20 years after the introduction of indocyanine green angiography (ICGA), and more than 10 years since the introduction of optical coherence tomography (OCT), it is time for a comprehensive presentation of the current technical and clinical aspects of these diagnostic methods, which is contained in this book. Recent technologic developments in digital video imaging have allowed ICGA and FA better resolution and offer new opportunities to investigate the dynamics of the normal choroid circulation and correlate them with the retinal counterpart in a variety of choroidal abnormalities and retinal diseases. In addition, since the invention of OCT, this technology has emerged to become a widely used tool that has already revolutionized the diagnosis and therapy of eye disease. Optical coherence tomography has already produced wide changes in the way the eye is examined and in the way patients are treated. It is only natural to combine the topics of retinal angiography and OCT for the diagnosis and follow-up of eye diseases.

This book includes contributions from an internationally renowned group of experts from the United States, Spain, Mexico, Costa Rica, Italy, and Venezuela, and has been divided into three parts. Part I, Fluorescein and Indocyanine Green Angiography, includes nine chapters on retinal photography and angiography via film and digital imaging techniques, fluorescein, and ICGA, and discusses general aspects and interpretation; angiography of macular diseases, retinal vascular diseases, inflammatory diseases, optic nerve diseases, and retinal and choroidal tumors; and retinal angiography in pharmacologic retinal toxicity. Part II, Optical Coherence Tomography, includes 12 chapters on how OCT works; the basic principles of OCT; OCT in macular diseases, diabetic retinopathy, and age-related macular degeneration; the role of OCT imaging in the evaluation of ocular photodynamic therapy and antiangiogenic therapy; OCT in tractional maculopathies, ocular inflammatory diseases, glaucoma, optic nerve diseases, and intraocular tumors; and limitations in the evaluation of OCT images. Part III, Ophthalmic Imaging, Spectral Domain, and New Technologies, includes six chapters on ophthalmic fundus imaging, ultrawide-angle fluorescein angiography, fundus autofluorescence, ultrahighresolution OCT, high-speed Fourier domain OCT, and spectral OCT/scanning laser ophthalmoscope (SLO).

The impetus to edit this book has come from my students and my colleagues. In addition, I have felt the need for a book on a combination of topics that I have been working on for a long time, including courses at the American Academy of Ophthalmology. I call this book a hybrid of angiography and optical coherence tomography. I think, as a retina specialist, that this combination will be very appealing to my colleagues and students throughout the ophthalmic community. Furthermore, ICGA (an important topic in the angiography part of this book) has been the topic of very few books. The book is intended for retina and vitreous specialists, retina and vitreous fellows, ophthalmology residents, and comprehensive ophthalmologists.

The principal objective of this text is to present current information on retinal and choroidal angiography as well as OCT imaging interpretation from leading experts in the field. We hope their knowledge and experience will assist ophthalmologists and retina specialists approach a level of knowledge about angiography and OCT to benefit the patients in their clinical practice.

J. Fernando Arevalo, MD, FACS 


\title{
Foreword
}

The field of ophthalmic fundus angiography is not new. Many articles and textbooks have been written on the subject. The field of optical coherence tomography, on the other hand, is still very much in its infancy. To bring these two critically important imaging techniques together in one comprehensive textbook was a monumental task. J. Fernando Arevalo set out to write a textbook whose principal objective was "to present current information on retinal and choroidal angiography as well as OCT imaging interpretation." This outstanding vitreoretinal specialist has clearly achieved his goal in the publication of this superbly organized and comprehensive text.

The techniques of fluorescein angiography and indocyanine green angiography are well known to all of us. The nuances of these techniques, however, require constant study and refinement. We are continually learning new things about the many disease states we study and treat on a day-to-day basis from our understanding of FA and ICG. Further clarification is always needed and always appreciated by those interested in these important areas of study. In the first section of this textbook the authors take us through a complete educational voyage of these imaging techniques. They begin with the very basics of both FA and ICG in very clear and eloquently written chapters. Choroidal, retinal vascular, and optic disc conditions are described and beautifully illustrated for the readers. For the novice this proves to be invaluable, while for the more advanced reader, the information is concise and serves as a wonderful resource for future reference.

The second section of the book deals with the new and exciting field of optical coherence tomography. The authors take this new field of imaging and, in a wonderfully orchestrated sequence of topics and chapters, develop and discuss OCT from the most basic principles needed to understand how OCT works to how it is applied to different disease states. Again, choroidal, retinal, and optic disc diseases are comprehensively discussed. Understanding that a picture is worth a thousand words and that images help the reader understand the concepts being described in the written text, the chapters contain a generous number of illustrations.

Finally, this textbook's last section deals with ophthalmic imaging, spectral domain, and new technologies, which to me is another way of saying computer processed imaging. If it were not for computers and their ability to process data, we would still be using film based FAs and ICGs. The authors delve into the difficult topic of fundus imaging and provide us today with a foundation for understanding ophthalmic imaging in the future.

Fernando Arevalo has assembled an excellent list of contributors who represent the "Who's Who" in their areas of expertise. With such a list of authors we have no reason to expect anything but the most current information in each of the chapters presented in this textbook. We are not disappointed in the result of their endeavors. We are pleased that Fernando and his coauthors have achieved their goal of producing a comprehensive text that brings together FA, ICG, and OCT in a single textbook that brings to us the most current knowledge on the topics discussed.

We have come a long way since the first photographic image of the retinal fundus. The authors of this book are distinguished authorities in their fields of interest, and have been given an opportunity to discuss and illustrate current topics of extreme importance in our care of patients and our understanding of the diseases that affect them. We are the beneficiaries of their experience and their willingness to share their knowledge and expertise with us. This textbook will be an important part of any library.

\author{
Alexander J. Brucker, M.D. \\ Professor of Ophthalmology \\ Scheie Eye Institute \\ University of Pennsylvania \\ Editor-in-Chief \\ RETINA, The Journal of \\ Retinal and Vitreous Diseases
}




\section{Contents}

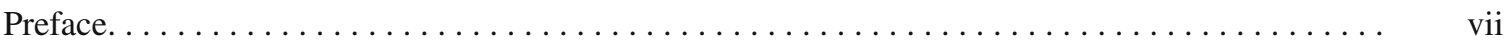

Foreword $\ldots \ldots \ldots \ldots \ldots \ldots \ldots \ldots \ldots \ldots \ldots \ldots \ldots \ldots \ldots \ldots \ldots \ldots \ldots$

\section{Part I Fluorescein and Indocyanine Green Angiography}

1. Retinal Photography and Angiography via Film and Digital Imaging Techniques $\ldots \ldots \ldots \ldots \ldots \ldots \ldots \ldots \ldots \ldots \ldots \ldots \ldots \ldots \ldots \ldots \ldots$

Thomas M. Clark

2. Fluorescein Angiography: General Principles and Interpretation $\ldots \ldots \ldots \ldots \ldots \ldots \ldots$ Bernard R. Hurley and Carl D. Regillo

3. Indocyanine Green Angiography: General Aspects and Interpretation . . . . . . . . . . . Christina M. Klais, Michael D. Ober, and Lawrence A. Yannuzzi

4. Angiography of Macular Diseases

Lihteh Wu, Raquel Benavides, Andrea Porras,

Rafael A. Garcia-Amaris, and J. Fernando Arevalo

5. Angiography of Retinal Vascular Diseases . . . . . . . . . . . . . . . . . . .

Lihteh Wu, Andrea Porras, Raquel Benavides, David G. Zeballos,

and J. Fernando Arevalo

6. Angiography of Inflammatory Diseases in Immunocompetent and Immunocompromised Patients $\ldots \ldots \ldots \ldots \ldots \ldots \ldots \ldots \ldots \ldots \ldots \ldots \ldots \ldots \ldots \ldots \ldots \ldots \ldots$ J. Fernando Arevalo, Reinaldo A. Garcia,

Lourdes Arellanes-Garcia, and Jans Fromow-Guerra

7. Angiography of Optic Nerve Diseases. . . . . . . . . . . . . . . . . . . J. Fernando Arevalo, Reinaldo A. Garcia, Juan G. Sanchez, Lihteh Wu, Dario Fuenmayor-Rivera, and Aura Giral

8. Angiography of Retinal and Choroidal Tumors. . . . . . . . . . . . . . . . . . J. Fernando Arevalo, Carol L. Shields, Jerry A. Shields, Miguel A. Materin, and Aristides J. Mendoza

9. Angiography in Pharmacologic Retinal Toxicity. . . . . . . . . . . . . . . . . . Stephen G. Schwartz and William F. Mieler

\section{Part II Optical Coherence Tomography (OCT)}

10. How Does Optical Coherence Tomography Work? Basic Principles

J. Fernando Arevalo, Daniel Krivoy, and Carlos F. Fernandez. 
11. Clinical Applications of Optical Coherence

Tomography in Macular Diseases . . . . . . . . . . . . . . . . . . . . . .

J. Fernando Arevalo, Aristides J. Mendoza,

Carlos F. Fernandez, Juan G. Sanchez, and Reinaldo A. Garcia

12. Clinical Applications of Optical Coherence Tomography

in Diabetic Retinopathy . . . . . . . . . . . . . . . . . . . . . . . . .

J. Fernando Arevalo, Carlos F. Fernandez, and Aristides J. Mendoza

13. Clinical Applications of Optical Coherence Tomography

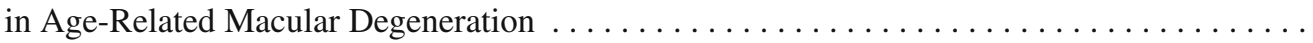

J. Fernando Arevalo and Reinaldo A. Garcia

14. The Role of Optical Coherence Tomography in the Evaluation

of Ocular Photodynamic Therapy . . . . . . . . . . . . . . . . . . . . . . . .

Caroline R. Baumal and Rubin W. Kim

15. The Role of Optical Coherence Tomography

in Anti-Vascular Endothelial Growth Factor Therapies ......................

Anne Fung, Nikolas London, and Philip Rosenfeld

16. Optical Coherence Tomography Findings

in Vitreomacular Interface Disorders. . . . . . . . . . . . . . . . . . . . . . . .

Javier Elizalde, Santiago Abengoechea, and María F. de la Paz

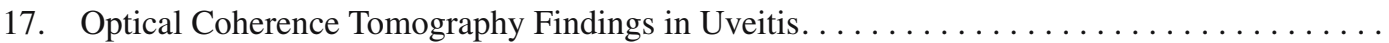
Anil Vedula and Janet L. Davis

18. Clinical Applications of Optical Coherence Tomography in Glaucoma .................

Daniel Krivoy, Noga Harizman, Celso Tello, and Jeffrey Liebmann

19. Clinical Applications of Optical Coherence Tomography

in Optic Nerve Disease . . . . . . . . . . . . . . . . . . . . . . . . . . . .

Emely Z. Karam, Thomas R. Hedges III, and Carlos E. Mendoza

20. Clinical Applications of Optical Coherence Tomography

in Intraocular Tumors. . . . . . . . . . . . . . . . . . . . . . . . . . . . . . . . . . .

Carol L. Shields, Miguel A. Materin, and Jerry A. Shields

21. Artifacts and Limitations in Time-Domain Optical Coherence Tomography Images. . . . . . .

J. Fernando Arevalo, Juan G. Sanchez, and Reinaldo A. Garcia

\section{Part III Ophthalmic Imaging, Spectral Domain, and New Technologies}

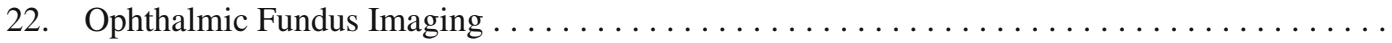

Michael D. Ober, Lawrence A. Yannuzzi, Jason S. Slakter, Richard F. Spaide,

Yale L. Fisher, Robert W. Flower, Richard Rosen, Christina M. Klais, and Nicole E. Gross

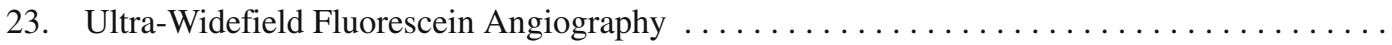

Scott C.N. Oliver and Steven D. Schwartz

24. Fundus Autofluorescence. .......................................... 
25. Future of Optical Coherence Tomography: Ultrahigh-Resolution Versus

Standard-Resolution OCT . . . . . . . . . . . . . . . . . . . . . . . . . .

Jay S. Duker, Lelia Adelina Paunescu, and James G. Fujimoto

26. Spectral/Fourier Domain Optical Coherence Tomography .....................

Royce W.S. Chen, James G. Fujimoto, and Jay S. Duker

27. Spectral Optical Coherence Tomography/Scanning

Laser Ophthalmoscope: The Next Generation. .........................

Richard B. Rosen and Patricia M.T. Garcia

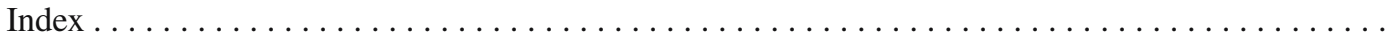




\section{Contributors}

Santiago Abengoechea, $M D$

Vitreoretinal Surgery Service, Centro de Oftalmología Barraquer, Barcelona, Spain

Lourdes Arellanes-Garcia, MD

Uveitis and Intraocular Inflammation Service, Asociación para la Prevención de la Ceguera, Mexico City, Mexico

J. Fernando Arevalo, MD, FACS

Retina and Vitreous Service, Clinica Oftalmológica Centro Caracas, Arevalo-Coutinho Foundation for Research in Ophthalmology, Caracas, Venezuela

Caroline R. Baumal, MD

Tufts University School of Medicine, Vitreoretinal Service, New England Eye Center, Boston, Massachusetts

Raquel Benavides, $M D$

Department of Ophthalmology, Hospital Mexico, San Jose, Costa Rica

Royce W.S. Chen, BA

Tufts University School of Medicine, Vitreoretinal Service, New England Eye Center, Boston, Massachusetts

Antonio P. Ciardella, MD

Director of Ophthalmology, Denver Health Medical Center, Associate Professor of Ophthalmology, University of Colorado Health Science Center, Denver, Colorado

Thomas M. Clark, BSc, CRA

Department of Ophthalmology, Shiley Eye Center, Ophthalmic Photography and Electronic Imaging

Department, University of California, San Diego, San Diego, California

Janet L. Davis, $M D$

Uveitis and Intraocular Inflammation Service, Bascom Palmer Eye Institute, University of Miami Miller

School of Medicine, Miami, Florida

María F. de la Paz, MD

Centro de Oftalmología Barraquer, Barcelona, Spain

Jay S. Duker, $M D$

Tufts University School of Medicine, Vitreoretinal Service, New England Eye Center, Boston, Massachusetts

Chiara M. Eandi, $M D, P h D$

Eye Clinic University of Torino, Torino, Italy

Javier Elizalde, $M D$

Vitreoretinal Surgery Service, Centro de Oftalmología Barraquer, Barcelona, Spain 
Carlos F. Fernandez, MD

Retina and Vitreous Service, Clinica Oftalmológica Centro Caracas, Arevalo-Coutinho Foundation for Research in Ophthalmology, Caracas, Venezuela

Yale L. Fisher, MD

LuEsther T. Mertz Retinal Research Center, Manhattan Eye, Ear and Throat Hospital, Department of Ophthalmology, New York, New York

Robert W. Flower, DSC

LuEsther T. Mertz Retinal Research Center, Manhattan Eye, Ear and Throat Hospital, Department of Ophthalmology, New York, New York, USA

Jans Fromow-Guerra, MD

Retina and Vitreous Service, Asociación para la Prevención de la Ceguera, Mexico City, Mexico

Dario Fuenmayor-Rivera, $M D$

Instituto de Oftalmologia y Otorrinolaringologia, Caracas, Venezuela

James G. Fujimoto, PhD

Research Laboratory of Electronics and Department of Electrical Engineering and Computer Science, Massachusetts Institute of Technology, Cambridge, Massachusetts

Anne Fung, MD

Pacific Eye Associates, California Pacific Medical Center, San Francisco, California

Patricia M.T. Garcia, MD

Advanced Retinal Imaging Laboratory, New York Eye and Ear Infirmary, New York, New York, Department of Ophthalmology, New York Medical College, Valhalla, New York

Reinaldo A. Garcia, MD

Retina and Vitreous Service, Clinica Oftalmológica Centro Caracas, Arevalo-Coutinho

Foundation for Research in Ophthalmology, Caracas, Venezuela

Rafael A. Garcia-Amaris, MD

Retina and Vitreous Service, Clinica Oftalmológica Centro Caracas, Arevalo-Coutinho

Foundation for Research in Ophthalmology, Caracas, Venezuela

Aura Giral, $M D$

Instituto de Oftalmologia y Otorrinolaringologia, Caracas, Venezuela

Nicole E. Gross, MD

LuEsther T. Mertz Retinal Research Center, Department of Ophthalmology, Manhattan Eye,

Ear and Throat Hospital, New York, New York

Noga Harizman, MD

New York Eye and Ear Infirmary, New York, New York

Thomas R. Hedges III, MD

Tufts University School of Medicine, Neuro-Ophthalmology Service, New England Eye Center, Boston, Massachusetts

Bernard R. Hurley, MD

Retina Service, Wills Eye Hospital, Thomas Jefferson University, Philadelphia, Pennsylvania 
Emely Z. Karam, $M D$

Neuro-Ophthalmology Service, Unidad Oftalmologica de Caracas, Associacion Venezolana para el Avance de la Oftalmologia, Caracas, Venezuela

Rubin W. Kim, MD

Tufts University School of Medicine, Vitreoretinal Service, New England Eye Center, Boston, Massachusetts

Christina M. Klais, MD

LuEsther T. Mertz Retinal Research Center, Department of Ophthalmology, Manhattan Eye,

Ear and Throat Hospital, New York, New York

Daniel Krivoy, $M D$

New York Medical College, New York, New York, University of California at Los Angeles, Los Angeles, California

Jeffrey Liebmann, $M D$

New York Eye and Ear Infirmary, New York University, New York, New York

Nikolas London, $M D$

Pacific Eye Associates, California Pacific Medical Center, San Francisco, California

Miguel A. Materin, MD

Ocular Oncology Service, Wills Eye Hospital, Thomas Jefferson University, Philadelphia, Pennsylvania

Aristides J. Mendoza, MD

Retina and Vitreous Service, Clinica Oftalmológica Centro Caracas, Arevalo-Coutinho Foundation for

Research in Ophthalmology, Caracas, Venezuela

Carlos E. Mendoza, $M D$

Tufts University School of Medicine, Neuro-Ophthalmology Service, New England Eye Center, Boston, Massachusetts

William F. Mieler, MD

Professor and Chairman, Department of Ophthalmology \& Visual Science, University of Chicago, Chicago, Illinois

Michael D. Ober, $M D$

LuEsther T. Mertz Retinal Research Center, Department of Ophthalmology, Manhattan Eye,

Ear and Throat Hospital, New York, New York

Scott C.N. Oliver, $M D$

Department of Ophthalmology, Jules Stein Eye Institute, University of California Los Angeles, Los Angeles, California

Lelia Adelina Paunescu, PhD

Tufts University School of Medicine, Vitreoretinal Service, New England Eye Center, Boston, Massachusetts

Andrea Porras, $M D$

Department of Ophthalmology, Hospital Mexico, San Jose, Costa Rica

Carl D. Regillo, $M D$

Retina Service, Wills Eye Hospital, Thomas Jefferson University, Philadelphia, Pennsylvania 
Richard B. Rosen, MD, FACS, FASRS, CRA

Director of Ophthalmic Research, New York Eye and Ear Infirmary, New York, New York, Department of Clinical Ophthalmology, New York Medical College, Valhalla, New York, Department of Applied Optics, University of Kent, Canterbury, United Kingdom

Philip Rosenfeld, $M D$

Retina Service, Bascom Palmer Eye Institute, University of Miami Miller School of Medicine, Miami, Florida

Juan G. Sanchez, MD

Retina and Vitreous Service, Clinica Oftalmológica Centro Caracas, Arevalo-Coutinho

Foundation for Research in Ophthalmology, Caracas, Venezuela

Stephen G. Schwartz, MD

Bascom Palmer Eye Institute, University of Miami Miller School of Medicine, Naples, Florida

Steven D. Schwartz, MD

Retina Service, Department of Ophthalmology, Jules Stein Eye Institute, University of California

Los Angeles, Los Angeles, California

Carol L. Shields, MD

Ocular Oncology Service, Wills Eye Hospital, Thomas Jefferson

University, Philadelphia, Pennsylvania

Jerry A. Shields, $M D$

Ocular Oncology Service, Wills Eye Hospital, Thomas Jefferson University, Philadelphia, Pennsylvania

Jason S. Slakter, $M D$

LuEsther T. Mertz Retinal Research Center, Manhattan Eye, Ear and Throat Hospital,

Department of Ophthalmology, New York, New York

Richard F. Spaide, MD

LuEsther T. Mertz Retinal Research Center, Manhattan Eye, Ear and Throat Hospital,

Department of Ophthalmology, New York, New York

Celso Tello, $M D$

New York Medical College, New York, New York

Anil Vedula, MD

Bascom Palmer Eye Institute, University of Miami Miller School of Medicine, Miami, Florida

Lihteh $W u, M D$

Retina Service, Instituto de Cirugia Ocular, San Jose, Costa Rica

Lawrence A. Yannuzzi, MD

Department of Ophthalmology, Columbia University School of Medicine, Surgeon Director, Manhattan Eye, Ear, and Throat Hospital, Vitreous Retina Macula Consultants of New York, New York, New York

David G. Zeballos, MD

Retina and Vitreous Service, Clinica Oftalmológica Centro Caracas, Arevalo-Coutinho Foundation for Research in Ophthalmology, Caracas, Venezuela 